\title{
A Three-Echelon Dual-Channel Supply Chain Model with Learning Effect Under the Return Policy
}

\author{
Sujata Saha \\ Department of Mathematics, Mankar College, West Bengal, India \\ Corresponding author: sahasujata@outlook.com
}

\section{ARTICLE INFO}

\section{Article history}

Received May 14, 2021

Revised August 11, 2021

Accepted August 13, 2021

Available Online August 31, 2021

\section{Keywords}

Three-echelon

Refurbishment

Inspection

Learning effect

Return

\begin{abstract}
In today's competitive and technologically developed era, many retailers have adopted an e-channel to increase sales, in addition to the existing traditional retail channel. Although many researchers studied this issue, there is hardly any research that comprehensively considers the learning-effect and return-policy. Therefore, this research aimed to develop an imperfect production dual-channel supply chain model consisting of a supplier, a manufacturer, and a retailer. The manufacturer also has a refurbishment unit adjacent to its production hub, where it reworks all the defectives. The main objective is to maximize the supply chain profit by considering factors, such as inspection error, return policy, and learning-effect of the employees. Finally, this model is analyzed with the Leader-follower relationship strategy and an integrated approach. The research found that the integrated approach is profitable for the entire supply chain, while commodity prices can be minimized. Sensitivity analysis is also presented in this study.
\end{abstract}

This is an open-access article under the CC-BY-SA license.

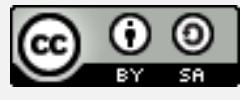

\section{Introduction}

Companies and business organizations are striving to develop marketing strategies to sustain their existence [1]. Supply chain management (SCM) is one such effective strategy that presents an integrated way to resolve business-related issues to ensure better customer service and optimize business profit [2-7]. In practice, defective products are caused by machinery fault, defective raw materials, and the lethargy of laborers for continuous work. A recent study by Lai, et al. [8] proposed a vendor-buyer supply chain (SC) model by considering an imperfect production system that regards the quality improvement investment as a function of the defect rate of the products. Sarkar and Moon [9] and Manna, et al. [4] offered a model in an out-of-control situation due to a higher production rate and a long production time. Furthermore, a recent study by Dey [10] proposed a model to compensate for the production of faulty items by setting a larger production lot size. Other studies on imperfect production include Gautam and Khanna [11] and Manna, et al. [12]. 
Defective products do not function the way good products do and may fail to function during their lifetime. This problem harms the company's reputation. Therefore, to avoid supplying defective goods, companies must screen all production outputs before selling them. Unfortunately, while performing this activity, SC companies often make common mistakes in product inspection. This issue has been highlighted in the studies by Singh and Gupta [13], Jauhari, et al. [14], Saha [15], Saha and Chakrabarti [16], Saha and Chakrabarti [17], and Pal and Mahapatra [18]. Moreover, the learning-effect of employees who perform tasks repeatedly is an essential factor in the production system. Continuous learning of the personnel may reduce the setup cost of the production system [19]. Tsao, et al. [20] also stated that a reduction in the production time might occur due to the lack of personnel learning-induced adeptness. Another study by Yadav, et al. [21] investigated this factor on the loss and benefit in the system.

Recently, the increasing trend in shopping through e-channel encourages researchers to develop supply chain models that consider e-channel. Zhou, et al. [22] developed a pricing strategy in the dual-channel SC model that considers asymmetric information. $\mathrm{Zu}$, et al. [23] studied the optimal pricing strategies in a manufacturerretailer SC model. They analyzed the impact of green products on the chain's profit using the Nash equilibrium and the Stackelberg game approach. Heydari, et al. [24] developed an environmentally friendly dual-channel SC model. The distributor sells the products to the customers through the e-channel and retailer. Zhou and Ye [25] offered a differential game model involving a single manufacturer and a single retailer under a low carbon environment. Their model considered the dependence of the demand rate on carbon emission reduction, goodwill, and retail price. In this model, they found the dual-channel more effective in reducing carbon emission and profitable for the manufacturer. In reality, the vendors encourage the buyers to buy more products from them by offering some coordination policy, such as the return policy, to increase their sales. Under this policy, the buyers enjoy the liberty to return the defective products to the vendors, making it economically more sense to buy more products from this seller [26]. Research by Batarfi, et al. [27] in a reverse logistics dual-channel supply chain model showed that return policy benefits the system. Moreover, a study from Blanco-Montenegro, et al. [28] found that the SC expenses can be reduced by lowering the remanufacturing costs. In A dual-channel SC model, Li, et al. [29] found that the product returns via direct and indirect channels are effective only when the return rate is low. Likewise, a study by Mawandiya, et al. [30] showed that the SC cost could be reduced when the returned items are limited.

Based on the above literature review, this study designed a dual-channel SC model to maximize the SC profit. The proposed model employed a three-echelon dual-channel SC model with inspection error, return policy, and learning-effect. Due to the development of e-commerce, many customers are choosing the online channel to buy products. Being accustomed to the working environment, the workers work efficiently than ever, while at the same time lowering wastage of raw materials and the other necessary resources. Consequently, the production cost decreases gradually with time. As far as this research is concerned, no study examined the production and the pricing decisions in a threeechelon supply chain model under return-contract conditions while considering the role of the refurbishment unit of the manufacturer that reworks all the defective items.

Therefore, to address this research gap, this paper presents a three-echelon dualchannel supply chain model that considers a single supplier, a manufacturer, and a retailer. The manufacturer composes products in its core production unit using the raw materials supplied by the supplier and sells the perfect outputs to the retailer after inspection. The manufacturer offers a return contract to the retailer to send back defective products (due to inspection errors) supplied by the manufacturer. The manufacturer 
reworks all the defective items, including those received from the retailer in the refurbishment unit adjacent to the main production block, and sells these products directly to the customers in the market at a reduced price. The retailer sells the commodities from the retail shop and through an online channel. Moreover, the profit functions of each of the supply chain players, as well as the whole supply chain system, have been derived. Finally, the learning effect induced from the efficiency of the employees results in a decrease in the production cost. This proposed model will be analyzed using a leaderfollower relationship strategy and integrated approach. The main principle of SC is to provide commodities to the customers at a lower price while at the same time optimizing total profit. This study will investigate the production and pricing policies that may aid in achieving these goals. The findings of this study may provide some insights to the practitioners and future researchers.

The structure of this paper is presented as follows: notations and assumptions, mathematical models, solution methods, and numerical examples are presented in section 2 . Section 3 presents results and discussion. The last section of this paper is the conclusion.

\section{Methods}

\subsection{Notations and assumptions}

\subsubsection{Notations}

This study uses notations to facilitate mathematical modeling. The following notations are used to develop the model.

$I_{1 m}(t)$ : the inventory level at time $t$ of the manufacturer (in the main production unit).

$I_{2 m}(t)$ : the inventory level at time $t$ of the manufacturer (in the refurbishment unit).

$I_{r}(t) \quad$ : the inventory level at time $t$ of the retailer.

$D_{m} \quad$ : the demand rate of the manufacturer to the supplier.

$D_{c} \quad$ : the total demand rate of the customer to the retailer, where $D_{c}=D_{1}+D_{2}$, where $D_{1}$ is the retail shop's demand and $D_{2}$ is the e-channel's demand.

$D_{c}^{\prime} \quad$ : the demand rate of the customers for the refurbished products to the manufacturer.

$D_{r} \quad$ : the demand rate of the retailer to the manufacturer.

$A_{s} \quad$ : the ordering cost of the supplier.

$A_{m} \quad$ : the setup cost of the manufacturer for the main production unit.

$A_{m}^{\prime} \quad$ : the setup cost of the manufacturer for the refurbishment unit.

$A_{r} \quad$ : the ordering cost of the retailer.

$h_{s} \quad$ : the holding cost per unit item per unit time of the supplier.

$h_{m} \quad$ : the holding cost per unit perfect item per unit time of the manufacturer (in the main production unit).

$h_{m}^{\prime} \quad$ : the holding cost per unit imperfect item per unit time of the manufacturer (in the refurbishment unit).

$h_{r} \quad$ : the holding cost per unit item per unit time of the retailer.

$P_{S} \quad$ : the purchasing cost per unit of the raw materials of the supplier.

$P_{S}^{\prime} \quad$ : the salvage value per unit of the defective raw materials of the supplier.

$C_{S} \quad$ : inspection cost per unit raw material of the supplier.

$C_{m} \quad$ : inspection cost per unit item of the manufacturer.

$C_{r} \quad$ : inspection cost per unit item of the retailer.

$S_{e} \quad$ : selling price per unit item of the retailer in the e-channel. 
$y \quad$ : the percentage of non-conforming raw materials received by the supplier.

$z \quad$ : the percentage of defective products produced by the manufacturer in the main production unit.

$x \quad$ : the percentage of defective products received by the retailer.

$C_{p} \quad$ : production cost per unit item of the manufacturer.

$f_{c} \quad$ : refurbishment cost per unit defective items of the manufacturer.

$S_{S} \quad$ : selling price per unit raw material of the supplier.

$S_{m} \quad$ : selling price per unit perfect item of the manufacturer, i.e. purchasing cost per unit item of the retailer.

$\Pi_{s} \quad$ : total profit of the supplier.

$\Pi_{m} \quad$ : total profit of the manufacturer.

$\Pi_{r} \quad$ : total profit of the retailer.

$\Pi_{L} \quad$ : total profit of the supply chain while using the Leader-follower relationship strategy.

$\Pi_{I} \quad$ : total profit of the supply chain while using an integrated approach.

Decision variables

$Q \quad$ : the lot size of the supplier.

$P_{m} \quad$ : the production rate of the manufacturer

$S_{r} \quad$ : retail price per unit item of the retailer.

\subsubsection{Assumptions}

In the proposed model, the assumptions used include:

- The manufacturer's demand rate for raw material to the supplier is higher than the production rate of the items to get rid of the shortage of raw materials in the production period, i.e., $D_{m} \geq P_{m}$.

- Due to the learning effect of the employees, the production cost of the manufacturer decreases gradually with time. Here the research assumed the production cost as $C_{p}=\left(\alpha+e^{-\beta t}\right)$, where $\alpha, \beta>0$ are constant, and $\beta$ is the learning parameter.

- The retailer's every channel's demand rate is reversely affected by its own selling price and directly relates to the other channel's price. Therefore, this research assumed $D_{1}=a-b_{1} S_{r}+b_{1}^{\prime} S_{e}$ and $D_{2}=a-$ $b_{2} S_{e}+b_{2}^{\prime} S_{r}, a, \mathrm{~b}_{1}, \mathrm{~b}_{1}^{\prime}, \mathrm{c}, \mathrm{d}$ are positive constants, where $b_{1}>b_{2}^{\prime}$ and $b_{2}>b_{1}^{\prime}$, i.e., the individual channel prices impact more on respective demand than the cross channel prices.

\subsection{Mathematical model}

Mathematical formulation for the models for supplier, manufacturer, and retailer is presented in this section. The illustration of the problem in this supply chain system is depicted in Fig. 1.

The supplier purchases raw materials in a lot size Q. The supplier inspects the entire raw materials immediately after receiving them and supplies the good quality raw materials to the manufacturer. The fraction of defective items observed by the supplier is $y$. Therefore, the amount of perfect quality raw materials $=(1-y) Q$, which the retailer sells to the manufacturer at a rate $D_{m}$ during $\left(0, t_{1}\right)$. The manufacturer starts production 
at a rate $p_{m}$ at time $t=0$ and continues up to time $t=t_{1}$. Its inventory level reduces due to retailer's demand and reaches the zero level at time $t=t_{3}$. The manufacturer collects all the defective products from the main production unit and retailer and then sends them to the refurbishment unit. The refurbishment unit reworks these defective products and sells these directly to the customers at a rate $D_{c}^{\prime}$ during $\left(0, t_{1}\right)$. The retailer purchases the commodity from the manufacturer during $\left(0, t_{3}\right)$ at a rate $D_{r}$. Its inventory level depletes due to the customers' demand at a rate $\mathrm{D}_{\mathrm{c}}$ and reaches the zero level at time $t=T$.

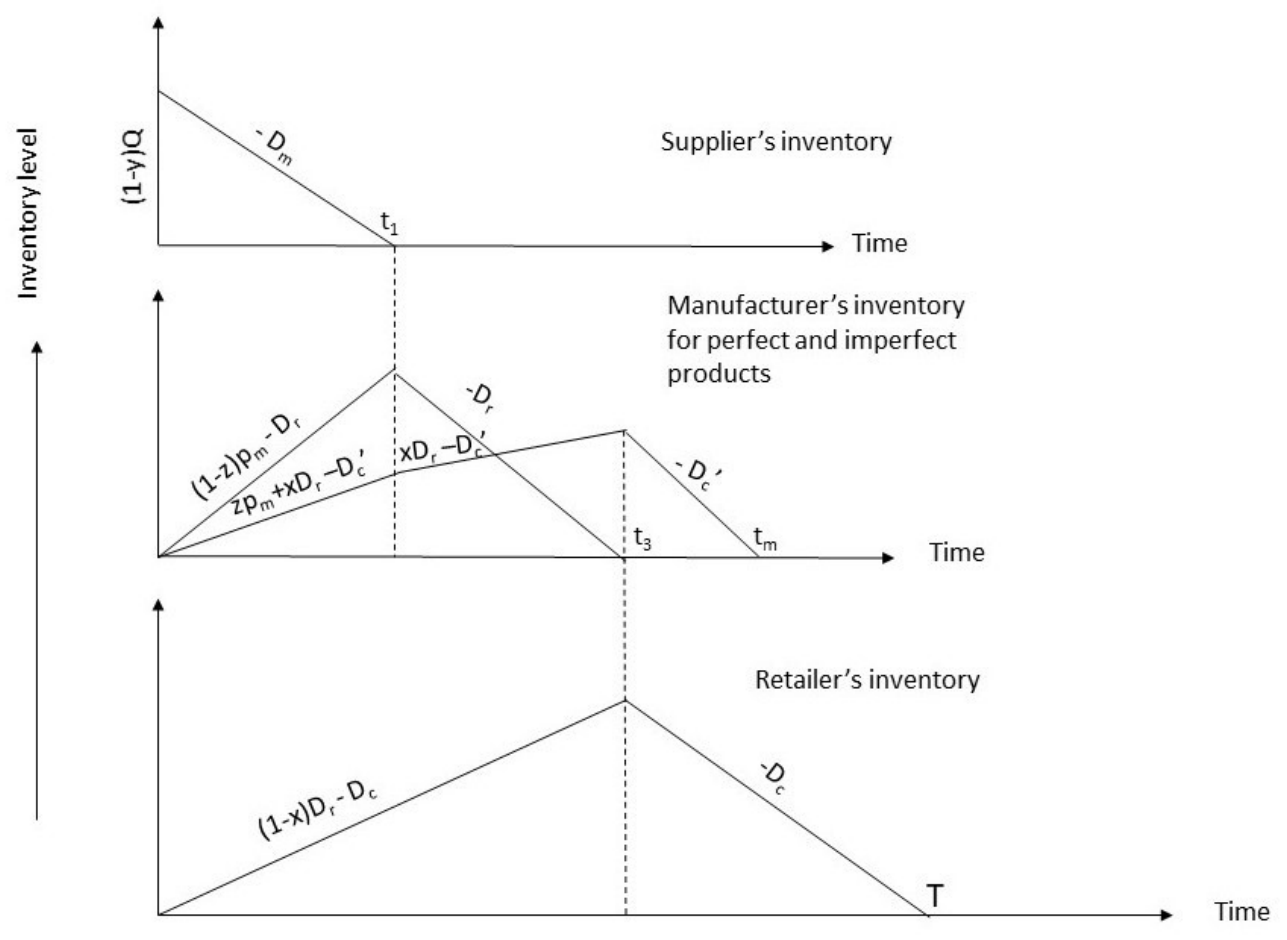

Fig. 1, Pictorial representation of this model.

\subsubsection{Supplier's model}

Here, the supplier sells $(1-y) Q$ units of raw materials to the manufacturer at a rate $D_{m}$ during $\left(0, t_{1}\right)$ in equation (1). Therefore,

$t_{1}=\frac{(1-y) Q}{D_{m}}$

The mathematical model of holding the cost of the raw materials at retailers is presented as follows:

$h_{s}\left\{\frac{1}{2}(1-y) Q t_{1}\right\}=\frac{h_{s}\{(1-y) Q\}^{2}}{2 D_{m}}$

Therefore, the total profit of the supplier can be seen in equation (2).

$\Pi_{s}=\left\{S_{s}(1-y)+P_{s}^{\prime} y\right\} Q-\left\{A_{s}+\left(P_{s}+C_{s}\right) Q+\frac{h_{s}(1-y)^{2} Q^{2}}{2 D_{m}}\right\}$ 


\subsubsection{Manufacturer's model}

In this section, a mathematical model is proposed at the manufacturer level. For the mathematical model in the main production unit, the differential equations in equation (3) represent the rate of change of inventory level for the perfect quality items of the manufacturer.

$$
\frac{d I_{1 m}(t)}{d t}= \begin{cases}(1-z) p_{m}-D_{r}, & 0 \leq t \leq t_{1} \\ -D_{r}, & t_{1} \leq t \leq t_{3}\end{cases}
$$

With $I_{1 m}(0)=0$ and $I_{1 m}\left(t_{3}\right)=0$. Solving differential equations in equation (3), we get $I_{1 m}(t)$ which is presented in equation (4).

$$
I_{1 m}(t)= \begin{cases}\left\{(1-z) p_{m}-D_{r}\right\} t, & 0 \leq t \leq t_{1} \\ -D_{r}\left(t-t_{3}\right), & t_{1} \leq t \leq t_{3}\end{cases}
$$

From the continuity condition of $I_{1 m}(t)$ at $t=t_{1}$, we have $\left\{(1-z) p_{m}-D_{r}\right\} t_{1}=$ $-D_{r}\left(t_{1}-t_{3}\right)$. Therefore, $t_{3}$ is formulated in equation (5).

$$
t_{3}=\frac{(1-z) p_{m} t_{1}}{D_{r}}=\frac{(1-y)(1-z) p_{m} Q}{D_{m} D_{r}}
$$

Subsequently, set up cost of the manufacturer is $A_{m}$. The production cost of the manufacturer is formulated as $\int_{0}^{t_{1}} p_{m} C_{p} d t$. Therefore, the detailed Production cost of the manufacturer is modeled as $p_{m} \int_{0}^{t_{1}}\left(\alpha+e^{-\beta t}\right) d t=p_{m}\left\{\alpha t_{1}-\frac{1}{\beta}\left(e^{-\beta t_{1}}-1\right)\right\}=p_{m}\left\{\frac{\alpha(1-y) Q}{D_{m}}-\right.$ $\left.\frac{1}{\beta}\left(e^{-\frac{\beta(1-y) Q}{D_{m}}}-1\right)\right\}$.

The inspection cost is formulated by $\frac{C_{m} p_{m}(1-y) Q}{D_{m}}$. Moreover, holding cost for perfect quality items is modeled by $h_{m}\left[\int_{0}^{t_{1}} I_{1 m}(t) d t+\int_{t_{1}}^{t_{3}} I_{1 m}(t) d t\right]=h_{m}\left[\int_{0}^{t_{1}}\left\{(1-z) p_{m}-\right.\right.$ $\left.\left.D_{r}\right\} t d t-\int_{t_{1}}^{t_{3}} D_{r}\left(t-t_{3}\right) d t\right]=\frac{h_{m}}{2}\left\{\left\{(1-z) p_{m}-D_{r}\right\} t_{1}^{2}+D_{r}\left(t_{1}-t_{3}\right)^{2}\right\}=\frac{h_{m}}{2}\left\{\left\{(1-z) p_{m}-\right.\right.$ $\left.\left.D_{r}\right\} t_{1}^{2}+\frac{\left\{(1-z) p_{m}-D_{r}\right\}^{2} t_{1}^{2}}{D_{r}}\right\}=\frac{h_{m}}{2} \frac{\left\{(1-z) p_{m}-D_{r}\right\}(1-z)(1-y)^{2} p_{m} Q^{2}}{D_{m}^{2} D_{r}}$

Therefore, the manufacturer's total cost in the main production unit is presented in equation (6).

$$
\begin{aligned}
& T C_{1 m}=A_{m}+p_{m}\left\{\frac{\alpha(1-y) Q}{D_{m}}-\frac{1}{\beta}\left(e^{-\frac{\beta(1-y) Q}{D_{m}}}-1\right)\right\}+\frac{C_{m} p_{m}(1-y) Q}{D_{m}}+ \\
& \frac{h_{m}}{2} \frac{\left\{(1-z) p_{m}-D_{r}\right\}(1-z)(1-y)^{2} p_{m} Q^{2}}{D_{m}^{2} D_{r}}
\end{aligned}
$$

The mathematical model for the refurbishment unit is expressed with differential equations in equation (7), describing the rate of change of the inventory level. 


$$
\frac{d I_{2 m}(t)}{d t}= \begin{cases}\left(z p_{m}+x D_{r}\right)-D_{c}^{\prime} & 0 \leq t \leq t_{1} \\ x D_{r}-D_{c}^{\prime} & t_{1} \leq t \leq t_{3} \\ -D_{c}^{\prime} & t_{3} \leq t \leq t_{m}\end{cases}
$$

With boundary conditions, $I_{2 m}(0)=0, I_{2 m}\left(t_{1}\right)=\left(z p_{m}+x D_{r}-D_{c}^{\prime}\right) t_{1}, I_{2 m}\left(t_{m}\right)=0$. Solving differential equations in equation (7), we have $I_{2 m}(t)$ that formulated in equation (8).

$$
I_{2 m}(t)=\left\{\begin{array}{lr}
\left(z p_{m}+x D_{r}-D_{c}^{\prime}\right) t & 0 \leq t \leq t_{1} \\
\left(x D_{r}-D_{c}^{\prime}\right) t+z p_{m} t_{1} & t_{1} \leq t \leq t_{3} \\
-D_{c}^{\prime}\left(t-t_{m}\right) & t_{3} \leq t \leq t_{m}
\end{array}\right.
$$

From the continuity condition of $I_{2 m}(t)$ at $t=t_{3}$ we have, $\left(x D_{r}-D_{c}^{\prime}\right) t_{3}+z p_{m} t_{1}=$ $-D_{c}^{\prime}\left(t_{3}-t_{m}\right)$. Therefore, $t_{m}=\frac{x D_{r} t_{3}+z p_{m} t_{1}}{D_{c}^{\prime}}$. detail formula $t_{m}$ is described in equation (9).

$t_{m}=\frac{\{x(1-z)+z\}(1-y) Q p_{m}}{D_{m} D_{c}^{\prime}}$

Set up cost is formulated as $A_{m}^{\prime}$, and the cost of refurbishment is $f_{c} D_{c}^{\prime} t_{3}=$ $\frac{f_{c} D_{c}^{\prime}(1-y)(1-z) p_{m} Q}{D_{m} D_{r}}$. Holding cost is formulated $h_{m}^{\prime}\left[\int_{0}^{t_{1}} I_{2 m}(t) d t+\int_{t_{1}}^{t_{3}} I_{2 m}(t) d t+\int_{t_{3}}^{t_{m}} I_{2 m}(t) d t\right]=$ $h_{m}^{\prime}\left[\int_{0}^{t_{1}}\left(z p_{m}+x D_{r}-D_{c}^{\prime}\right) t d t+\int_{t_{1}}^{t_{3}}\left\{\left(x D_{r}-D_{c}^{\prime}\right) t+z p_{m} t_{1}\right\} d t-\int_{t_{3}}^{t_{m}} D_{c}^{\prime}\left(t-t_{m}\right) d t\right]=\frac{h_{m}^{\prime}}{2}\left[\left(z p_{m}+\right.\right.$ $\left.\left.x D_{r}-D_{c}^{\prime}\right) t_{1}^{2}+\left(x D_{r}-D_{c}^{\prime}\right)\left(t_{3}^{2}-t_{1}^{2}\right)+2 z p_{m} t_{1}\left(t_{3}-t_{1}\right)+D_{c}^{\prime}\left(t_{3}-t_{m}\right)^{2}\right]$.

Putting the values of $t_{1}, t_{3}$ and $t_{m}$ from the equations (1), (5), and (9) respectively and simplifying them, we have the holding cost of the manufacturer in the refurbishment unit as $\quad \frac{h_{m}^{\prime}}{2}\left[z p_{m}\left\{\frac{2(1-z) p_{m}}{D_{r}}-1\right\} \frac{(1-y)^{2} Q^{2}}{D_{m}{ }^{2}}+\frac{\left(x D_{r}-D_{c}^{\prime}\right)(1-y)^{2}(1-z)^{2} p_{m}{ }^{2} Q^{2}}{D_{m}{ }^{2} D_{r}{ }^{2}}+D_{c}^{\prime}\left\{\frac{(1-z)}{D_{r}}-\right.\right.$ $\left.\left.\frac{x(1-z)+z}{D_{c}^{\prime}}\right\}^{2} \frac{(1-y)^{2} p_{m}^{2} Q^{2}}{D_{m}^{2}}\right]$.

Therefore, the manufacturer's total cost in the refurbishment unit can be seen in equation (10).

$$
\begin{aligned}
& T C_{2 m}=A_{m}^{\prime}+\frac{f_{c} D_{c}^{\prime}(1-y)(1-z) p_{m} Q}{D_{m} D_{r}}+\frac{h_{m}^{\prime}}{2}\left\{z p_{m}\left(\frac{2(1-z) p_{m}}{D_{r}}-1\right) \frac{(1-y)^{2} Q^{2}}{D_{m}^{2}}+\right. \\
& \left.\frac{\left(x D_{r}-D_{c}^{\prime}\right)(1-y)^{2}(1-z)^{2} p_{m}^{2} Q^{2}}{D_{m}^{2} D_{r}^{2}}+D_{c}^{\prime}\left(\frac{(1-z)}{D_{r}}-\frac{x(1-z)+z}{D_{c}^{\prime}}\right)^{2} \frac{(1-y)^{2} p_{m}^{2} Q^{2}}{D_{m}^{2}}\right\}
\end{aligned}
$$

The total revenue of the manufacturer obtained from selling the products is modeled by $S_{m}(1-x) D_{r} t_{3}+S_{m}^{\prime} D_{c}^{\prime} t_{m}=\frac{\left\{S_{m}(1-x)(1-z)+S_{m}^{\prime}(x(1-z)+z)\right\}(1-y) p_{m} Q}{D_{m}}$. Therefore, the total profit of the manufacturer is formulated by $\Pi_{m}=$ total revenue $-\left(T C_{1 m}+T C_{2 m}\right)$. Detail $\Pi_{m} \quad$ is $\quad$ as $\quad \Pi_{m}=\frac{\left\{S_{m}(1-x)(1-z)+S_{m}^{\prime}(x(1-z)+z)\right\}(1-y) p_{m} Q}{D_{m}}-\left[A_{m}+A_{m}^{\prime}+p_{m}\left\{\frac{\alpha(1-y) Q}{D_{m}}-\right.\right.$ $\left.\frac{1}{\beta}\left(e^{-\frac{\beta(1-y) Q}{D_{m}}}-1\right)\right\}+\frac{C_{m} p_{m}(1-y) Q}{D_{m}}+\frac{f_{c} D_{c}^{\prime}(1-y)(1-z) p_{m} Q}{D_{m} D_{r}}+\frac{h_{m}}{2} \frac{\left\{(1-z) p_{m}-D_{r}\right\}(1-z)(1-y)^{2} p_{m} Q^{2}}{D_{m}^{2} D_{r}}+$ $\left.\frac{h_{m}^{\prime}}{2}\left\{z p_{m}\left(\frac{2(1-z) p_{m}}{D_{r}}-1\right) \frac{(1-y)^{2} Q^{2}}{D_{m}{ }^{2}}+\frac{\left(x D_{r}-D_{c}^{\prime}\right)(1-y)^{2}(1-z)^{2} p_{m}{ }^{2} Q^{2}}{D_{m}{ }^{2} D_{r}{ }^{2}}+D_{c}^{\prime}\left(\frac{(1-z)}{D_{r}}-\frac{x(1-z)+z}{D_{c}^{\prime}}\right)^{2} \frac{(1-y)^{2} p_{m}{ }^{2} Q^{2}}{D_{m}{ }^{2}}\right\}\right]$ 


\subsection{3 retailer's model}

In this section, the model at the retail level is proposed. The following differential equations in equation (11) describe the rate of change of the inventory level of the retailer

$$
\frac{d I_{1 r}(t)}{d t}= \begin{cases}(1-x) D_{r}-D_{c}, & 0 \leq t \leq t_{3} \\ -D_{c}, & t_{3} \leq t \leq T\end{cases}
$$

With $I_{1 r}(0)=0$ and $I_{1 r}(T)=0$. Solving equation differential equations in equation (11), we have $I_{1 r}(t)$ that is formulated in equation (12).

$$
I_{1 r}(t)= \begin{cases}\left\{(1-x) D_{r}-D_{c}\right\} t, & 0 \leq t \leq t_{3} \\ -D_{c}(t-T), & t_{3} \leq t \leq T\end{cases}
$$

From the continuity condition of $I_{1 r}(t)$ at $t=t_{3}$ we have $\left\{(1-x) D_{r}-D_{c}\right\} t_{3}=$ $-D_{c}\left(t_{3}-T\right)$. Therefore, $T$ can be solved using equation (13).

$$
T=\frac{(1-x) D_{r}}{D_{c}} t_{3}=\frac{(1-x)(1-y)(1-z) p_{m} Q}{D_{m} D_{c}} .
$$

The ordering cost of the retailer is $A_{r}$, Purchasing cost is $S_{m}(1-x) D_{r} t_{3}=$ $\frac{S_{m}(1-x)(1-y)(1-z) p_{m} Q}{D_{m}}$. The inspection cost is modeled by $C_{r} D_{r} t_{3}=\frac{C_{r}(1-y)(1-z) p_{m} Q}{D_{m}}$. Holding cost is formulated by $h_{r}\left[\int_{0}^{t_{3}} I_{1 r}(t) d t+\int_{t_{3}}^{T} I_{1 r}(t) d t\right]=h_{r}\left[\int_{0}^{t_{3}}\left\{(1-x) D_{r}-D_{c}\right\} t d t-\int_{t_{3}}^{T} D_{c}(t-\right.$ $T) d t]=\frac{h_{r}}{2}\left[\left\{(1-x) D_{r}-D_{c}\right\} t_{3}^{2}+D_{c}\left(t_{3}-T\right)^{2}\right]=h_{r} \frac{(1-x)(1-y)^{2}(1-z)^{2}\left\{(1-x) D_{r}-D_{c}\right\} P_{m}^{2} Q^{2}}{2 D_{m}^{2} D_{r} D_{c}}$.

Therefore, the total revenue of the retailer obtained from selling the products is $S_{r} D_{c} T=\frac{S_{r}(1-x)(1-y)(1-z) p_{m} Q}{D_{m}}$. The total profit of the retailer can be seen in equation (14).

$$
\begin{aligned}
& \Pi_{r}=\frac{S_{r}(1-x)(1-y)(1-z) p_{m} Q}{D_{m}}-\left\{A_{r}+\frac{C_{r}(1-y)(1-z) p_{m} Q}{D_{m}}+\frac{S_{m}(1-x)(1-y)(1-z) p_{m} Q}{D_{m}}+\right. \\
& \left.h_{r} \frac{(1-x)(1-y)^{2}(1-z)^{2}\left\{(1-x) D_{r}-D_{c}\right\} P_{m}^{2} Q^{2}}{2 D_{m}{ }^{2} D_{r} D_{c}}\right\}
\end{aligned}
$$

\subsection{Solution method}

In this section, two strategies are used to analyze the model: (1) Leader-follower relationship strategy emphasizes that the supply chain members make their decisions sequentially to optimize their profit; i.e., first, a player (leader) fixes the decision variable, then the other members (followers) take their decision following the decision taken by the leader. (2) Integrated approach signifies that all the members make their decisions in an integrated way to optimize the total profit of the supply chain. In this model, the decision variables are the lot size of the supplier, the production rate of the manufacturer, and the selling price of the retailer. The purpose is to find the strategy that will be more profitable for the SC. 


\subsection{1 leader-follower relationship strategy}

In this model, the supplier first optimizes the decision variable. Then, following the decision, the manufacturer makes the next decision. Finally, the retailer optimizes the decision variable following both the supplier and the manufacturer. Since the total profit of the supply chain is the summation of the total profits of the supplier, manufacturer, and retailer, the concavity of their profit functions should be proven to optimize the chain's total profit.

Theorem 1. The supplier's profit function is concave.

Proof: The total profit of the supplier per unit time $\mathrm{I} \Pi_{s l}=\frac{1}{t_{1}}\left(\Pi_{s}\right)$

Therefore, $\Pi_{s l}$ can be seen in equation (15).

$$
\Pi_{s l}=\frac{\left\{S_{S}(1-y)+P_{s}^{\prime} y\right\} D_{m}}{(1-y)}-\left\{\frac{A_{S} D_{m}}{(1-y) Q}+\frac{\left(P_{s}+C_{S}\right) D_{m}}{(1-y)}+\frac{h_{s}(1-y) Q}{2}\right\}
$$

The next step is differentiating equation (15) with respect to Q. it is modeled in equation (16).

$$
\frac{\partial\left(\Pi_{S l}\right)}{\partial Q}=\frac{D_{m} A_{S}}{Q^{2}(1-y)}-\frac{h_{S}(1-y)}{2}
$$

And, $\frac{\partial^{2}\left(\Pi_{s l}\right)}{\partial Q^{2}}=-\frac{2 D_{m} A_{s}}{Q^{3}(1-y)}<0$

It proves that the supplier's profit function is concave. Therefore, the optimum value of $\mathrm{Q}$ by equating the right-hand side of equation (16) to zero is obtained.

Theorem 2. The manufacturer's profit function is concave.

Proof: The manufacturer's total profit per unit time is modeled in equation (17).

$$
\begin{aligned}
& \Pi_{m l}=\frac{1}{t_{m}}\left(\Pi_{m}\right)=\frac{S_{m}(1-x)(1-z) D_{c}^{\prime}}{\{x(1-z)+z\}}+S_{m}^{\prime} D_{c}^{\prime}-\left[\frac{\left(A_{m}+A_{m}^{\prime}\right) D_{m} D_{c}^{\prime}}{\{x(1-z)+z\}(1-y) Q p_{m}}+\frac{D_{m} D_{c}^{\prime}}{\{x(1-z)+z\}(1-y) Q}\left\{\frac{\alpha(1-y) Q}{D_{m}}-\right.\right. \\
& \left.\frac{1}{\beta}\left(e^{-\frac{\beta(1-y) Q}{D_{m}}}-1\right)\right\}+\frac{C_{m} D_{c}^{\prime}}{\{x(1-z)+z\}}+\frac{f_{c} D_{c}^{\prime 2}(1-z)}{D_{r}\{x(1-z)+z\}}+\frac{h_{m}}{2} \frac{D_{c}^{\prime}(1-y)(1-z)\left\{(1-z) p_{m}-D_{r}\right\} Q}{D_{m} D_{r}\{x(1-z)+z\}}+ \\
& \frac{h_{m}^{\prime}}{2}\left\{z\left(\frac{2(1-z) p_{m}}{D_{r}}-1\right) \frac{(1-y) D_{c}^{\prime} Q}{D_{m}\{x(1-z)+z\}}+\frac{D_{c}^{\prime}\left(x D_{r}-D_{c}^{\prime}\right)(1-y)(1-z)^{2} p_{m} Q}{D_{m} D_{r}^{2}\{x(1-z)+z\}}+D_{c}^{\prime 2}\left(\frac{(1-z)}{D_{r}}-\right.\right. \\
& \left.\left.\left.\frac{\{x(1-z)+z\}}{D_{c}^{\prime}}\right)^{2} \frac{(1-y) p_{m} Q}{\{x(1-z)+z\} D_{m}}\right\}\right]
\end{aligned}
$$

Differentiating equation (17) with respect to $p_{m}$, the following is the formula that is described in equation (18).

$$
\begin{aligned}
& \frac{\partial\left(\Pi_{m l}\right)}{\partial p_{m}}=\frac{\left(A_{m}+A_{m}^{\prime}\right) D_{m} D_{c}^{\prime}}{\{x(1-z)+z\}(1-y) Q p_{m}^{2}}-\frac{h_{m}}{2} \frac{D_{c}^{\prime}(1-y)(1-z)^{2} Q}{D_{m} D_{r}\{x(1-z)+z\}}-\frac{h_{m}^{\prime}}{2}\left\{\frac{2 z(1-z) D_{c}^{\prime}}{D_{r}\{x(1-z)+z\}}+\frac{D_{c}^{\prime}\left(x D_{r}-D_{c}^{\prime}\right)(1-z)^{2}}{D_{r}^{2}\{x(1-z)+z\}}+\right. \\
& \left.\left(\frac{(1-z)}{D_{r}}-\frac{\{x(1-z)+z\}}{D_{c}^{\prime}}\right)^{2} \frac{D_{c}^{\prime 2}}{\{x(1-z)+z\}}\right\} \frac{(1-y) Q}{D_{m}} \\
& \frac{\partial^{2}\left(\Pi_{m l}\right)}{\partial p_{m}{ }^{2}}=-\frac{2\left(A_{m}+A_{m}^{\prime}\right) D_{m} D_{c}^{\prime}}{\{x(1-z)+z\}(1-y) Q p_{m}^{3}}<0
\end{aligned}
$$


It proves that the manufacturer's profit function is concave. Therefore, the optimum value of the manufacturer's production rate by equating the right-hand side of equation (18) to zero is obtained.

Theorem 3. The retailer's profit function is concave.

Proof: The retailer's total profit per unit time is $\Pi_{r l}=\frac{1}{T}\left(\Pi_{r}\right)$ (equation (19))

$$
\Pi_{r l}=S_{r} D_{c}-\left\{\frac{A_{r} D_{m} D_{c}}{(1-x)(1-y)(1-z) p_{m} Q}+\frac{C_{r} D_{c}}{(1-x)}+S_{m} D_{c}+h_{r} \frac{(1-y)(1-z)\left\{(1-x) D_{r}-D_{c}\right\} p_{m} Q}{2 D_{m} D_{r}}\right\}
$$

where, $D_{c}=D_{1}+D_{2}=2 a-\left(b_{1}-b_{2}^{\prime}\right) S_{r}-\left(b_{2}-b_{1}^{\prime}\right) S_{e}$

Differentiating equation (19) with respect to $\mathrm{S}_{\mathrm{r}}$ the following is the equation obtained (equation 20):

$$
\begin{aligned}
& \frac{\partial \Pi_{r l}}{\partial S_{r}}=2 a-2\left(b_{1}-b_{2}^{\prime}\right) S_{r}-\left(b_{2}-b_{1}^{\prime}\right) S_{e}+\frac{A_{r} D_{m}\left(b_{1}-b_{2}^{\prime}\right)}{(1-x)(1-y)(1-z) p_{m} Q}+\frac{C_{r}\left(b_{1}-b_{2}^{\prime}\right)}{(1-x)}+S_{m}\left(b_{1}-b_{2}^{\prime}\right)- \\
& \frac{h_{r}(1-y)(1-z) p_{m} Q\left(b_{1}-b_{2}^{\prime}\right)}{2 D_{m} D_{r}}
\end{aligned}
$$

and,

$\frac{\partial^{2} \Pi_{r l}}{\partial S_{r}^{2}}=-2\left(b_{1}-b_{2}^{\prime}\right)<0$.

It proves that the retailer's profit function is concave. The optimum value of the retailer's decision variable is obtained by equating the right-hand side of equation (20) to zero.

\subsubsection{Integrated approach}

In this section, this research explained the implementation of the integrated approach. The supplier, manufacturer, and retailer take their decisions together in an integrated way to optimize the overall profit of the supply chain. As a result, the total profit of the supply chain per unit time is formulated in equations (21) and (22).

$$
\begin{aligned}
& \Pi=\frac{1}{T}\left(\Pi_{s}+\Pi_{m}+\Pi_{r}\right) \\
& \Pi=\frac{\left\{S_{S}(1-y)+P_{s}^{\prime} y\right\} D_{m} D_{c}}{(1-x)(1-y)(1-z) p_{m}}-\left\{\frac{A_{s} D_{m} D_{c}}{(1-x)(1-y)(1-z) p_{m} Q}+\frac{\left(P_{s}+C_{S}\right) D_{m} D_{c}}{(1-x)(1-y)(1-z) p_{m}}+\frac{h_{s}(1-y) D_{c} Q}{2(1-x)(1-z) p_{m}}\right\}+ \\
& \frac{\left\{S_{m}(1-x)(1-z)+S_{m}^{\prime}(x(1-z)+z)\right\} D_{c}}{(1-x)(1-z)}-\frac{D_{m} D_{c}}{(1-x)(1-y)(1-z) p_{m} Q}\left[A_{m}+A_{m}^{\prime}+p_{m}\left\{\frac{\alpha(1-y) Q}{D_{m}}-\right.\right. \\
& \left.\frac{1}{\beta}\left(e^{-\frac{\beta(1-y) Q}{D_{m}}}-1\right)\right\}+\frac{c_{m} p_{m}(1-y) Q}{D_{m}}+\frac{f_{c} D_{c}^{\prime}(1-y)(1-z) p_{m} Q}{D_{m} D_{r}}+ \\
& \frac{h_{m}}{2} \frac{\left\{(1-z) p_{m}-D_{r}\right\}(1-z)(1-y)^{2} p_{m} Q^{2}}{D_{m}^{2} D_{r}}+\frac{h_{m}^{\prime}}{2}\left\{z p_{m}\left(\frac{2(1-z) p_{m}}{D_{r}}-1\right) \frac{(1-y)^{2} Q^{2}}{D_{m}^{2}}+\right. \\
& \left.\left.\frac{\left(x D_{r}-D_{c}^{\prime}\right)(1-y)^{2}(1-z)^{2} p_{m}^{2} Q^{2}}{D_{m}^{2} D_{r}^{2}}+D_{c}^{\prime}\left(\frac{(1-z)}{D_{r}}-\frac{x(1-z)+z}{D_{c}^{\prime}}\right)^{2} \frac{(1-y)^{2} p_{m}^{2} Q^{2}}{D_{m}^{2}}\right\}\right]+S_{r} D_{c}- \\
& \left\{\frac{A_{r} D_{m} D_{c}}{(1-x)(1-y)(1-z) p_{m} Q}+\frac{C_{r} D_{c}}{(1-x)}+S_{m} D_{c}+h_{r} \frac{(1-y)(1-z)\left\{(1-x) D_{r}-D_{c}\right\} p_{m} Q}{2 D_{m} D_{r}}\right\}
\end{aligned}
$$

Now, the first derivative with respect to $Q$ is presented in equation (23). 


$$
\begin{aligned}
& \frac{\partial \Pi}{\partial Q}=\frac{\left(A_{s}+A_{m}+A_{m}^{\prime}+A_{r}\right) D_{m} D_{c}}{(1-x)(1-y)(1-z) p_{m} Q^{2}}-\frac{h_{s}(1-y) D_{c}}{2(1-x)(1-z) p_{m}}-\frac{h_{m}}{2} \frac{\left\{(1-z) p_{m}-D_{r}\right\}(1-y) D_{c}}{D_{m} D_{r}(1-x)}- \\
& \frac{h_{m}^{\prime}}{2}\left\{\frac{z\left(2(1-z) p_{m}-D_{r}\right)(1-y) D_{c}}{D_{m} D_{r}(1-x)(1-z)}+\frac{D_{c}\left(x D_{r}-D_{c}^{\prime}\right)(1-y)(1-z) p_{m}}{D_{m} D_{r}^{2}(1-x)}+D_{c}^{\prime}\left(\frac{(1-z)}{D_{r}}-\frac{x(1-z)+z}{D_{c}^{\prime}}\right)^{2} \frac{(1-y) p_{m}}{(1-x)(1-z) D_{m}}\right\}- \\
& h_{r} \frac{(1-y)(1-z)\left\{(1-x) D_{r}-D_{c}\right\} p_{m}}{2 D_{m} D_{r}}
\end{aligned}
$$

and,

$\frac{\partial^{2} \Pi}{\partial Q^{2}}=-\frac{2\left(A_{s}+A_{m}+A_{m}^{\prime}+A_{r}\right) D_{m} D_{c}}{(1-x)(1-y)(1-z) p_{m} Q^{3}}<0$.

Therefore, the profit function, in this case, is concave with respect to $Q$. The first derivative with respect to $p_{m}$ is presented in equation (24).

$$
\begin{aligned}
& \frac{\partial \Pi}{\partial p_{m}}=-\frac{\left\{S_{s}(1-y)+P_{s}^{\prime} y\right\} D_{m} D_{c}}{(1-x)(1-y)(1-z) p_{m}^{2}}+\frac{\left(A_{s}+A_{m}+A_{m}^{\prime}+A_{r}\right) D_{m} D_{c}}{(1-x)(1-y)(1-z) p_{m}^{2} Q}+\frac{\left(P_{s}+C_{s}\right) D_{m} D_{c}}{(1-x)(1-y)(1-z) p_{m}^{2}}+\frac{h_{s}(1-y) D_{c} Q}{2(1-x)(1-z) p_{m}^{2}}- \\
& \frac{h_{m}(1-y)(1-z) D_{c} Q}{2 D_{m} D_{r}(1-x)}-\frac{h_{m}^{\prime}}{2}\left\{\frac{2 z(1-y) D_{c} Q}{D_{m} D_{r}(1-x)}+\frac{D_{c}\left(x D_{r}-D_{c}^{\prime}\right)(1-y)(1-z) Q}{D_{m} D_{r}^{2}(1-x)}+D_{c}^{\prime}\left(\frac{(1-z)}{D_{r}}-\right.\right. \\
& \left.\left.\frac{x(1-z)+z}{D_{c}^{\prime}}\right)^{2} \frac{(1-y) Q}{D_{m}(1-x)(1-z)}\right\}-h_{r} \frac{(1-y)(1-z)\left\{(1-x) D_{r}-D_{c}\right\} Q}{2 D_{m} D_{r}}
\end{aligned}
$$

and,

$\frac{\partial^{2} \Pi}{\partial p_{m}^{2}}=-\frac{2}{p_{m}^{3}}\left\{\frac{\left(A_{s}+A_{m}+A_{m}^{\prime}+A_{r}\right) D_{m} D_{c}}{(1-x)(1-y)(1-z) Q}+\frac{\left(P_{s}+C_{s}\right) D_{m} D_{c}}{(1-x)(1-y)(1-z)}+\frac{h_{s}(1-y) D_{c} Q}{2(1-x)(1-z)}-\frac{\left\{S_{s}(1-y)+P_{s}^{\prime} y\right\} D_{m} D_{c}}{(1-x)(1-y)(1-z)}\right\}$

Therefore, the profit function is concave with respect to the production rate of the manufacturer, provided that,

$\frac{\left(A_{S}+A_{m}+A_{m}^{\prime}+A_{r}\right) D_{m} D_{c}}{(1-x)(1-y)(1-z) Q}+\frac{\left(P_{S}+C_{S}\right) D_{m} D_{c}}{(1-x)(1-y)(1-z)}+\frac{h_{S}(1-y) D_{c} Q}{2(1-x)(1-z)}-\frac{\left\{S_{S}(1-y)+P_{S}^{\prime} y\right\} D_{m} D_{c}}{(1-x)(1-y)(1-z)}>0$

The first derivative respect to $S_{r}$ is presented in equation (25).

$$
\begin{aligned}
& \frac{\partial \Pi}{\partial S_{r}}=-\frac{\left\{S_{S}(1-y)+P_{s}^{\prime} y\right\} D_{m}\left(b_{1}-b_{2}^{\prime}\right)}{(1-x)(1-y)(1-z) p_{m}}+\left(b_{1}-b_{2}^{\prime}\right)\left\{\frac{\left(A_{s}+A_{m}+A_{m}^{\prime}+A_{r}\right) D_{m}}{(1-x)(1-y)(1-z) p_{m} Q}+\frac{\left(P_{S}+C_{S}\right) D_{m}}{(1-x)(1-y)(1-z) p_{m}}+\right. \\
& \left.\frac{h_{S}(1-y) Q}{2(1-x)(1-z) p_{m}}\right\}-\frac{\left\{S_{m}(1-x)(1-z)+S_{m}^{\prime}(x(1-z)+z)\right\}\left(b_{1}-b_{2}^{\prime}\right)}{(1-x)(1-z)}+\frac{D_{m}\left(b_{1}-b_{2}^{\prime}\right)}{(1-x)(1-y)(1-z) p_{m} Q}\left[p _ { m } \left\{\frac{\alpha(1-y) Q}{D_{m}}-\right.\right. \\
& \left.\frac{1}{\beta}\left(e^{-\frac{\beta(1-y) Q}{D_{m}}}-1\right)\right\}+\frac{C_{m} p_{m}(1-y) Q}{D_{m}}+\frac{f_{c} D_{c}^{\prime}(1-y)(1-z) p_{m} Q}{D_{m} D_{r}}+\frac{h_{m}}{2} \frac{\left\{(1-z) p_{m}-D_{r}\right\}(1-z)(1-y)^{2} p_{m} Q^{2}}{D_{m}^{2} D_{r}}+ \\
& \frac{h_{m}^{\prime}}{2}\left\{z p_{m}\left(\frac{2(1-z) p_{m}}{D_{r}}-1\right) \frac{(1-y)^{2} Q^{2}}{D_{m}^{2}}+\frac{\left(x D_{r}-D_{c}^{\prime}\right)(1-y)^{2}(1-z)^{2} p_{m}^{2} Q^{2}}{D_{m}^{2} D_{r}^{2}}+D_{c}^{\prime}\left(\frac{(1-z)}{D_{r}}-\right.\right. \\
& \left.\left.\left.\frac{x(1-z)+z}{D_{c}^{\prime}}\right)^{2} \frac{(1-y)^{2} p_{m}^{2} Q^{2}}{D_{m}^{2}}\right\}\right]+2 a-2\left(b_{1}-b_{2}^{\prime}\right) S_{r}-\left(b_{2}-b_{1}^{\prime}\right) S_{e}+\left(b_{1}-b_{2}^{\prime}\right)\left\{\frac{A_{r} D_{m}}{(1-x)(1-y)(1-z) p_{m} Q}+\right. \\
& \left.\frac{C_{r}}{(1-x)}+S_{m}-h_{r} \frac{(1-y)(1-z) p_{m} Q}{2 D_{m} D_{r}}\right\}
\end{aligned}
$$

And,

$\frac{\partial^{2} \Pi}{\partial S_{r}^{2}}=-2\left(b_{1}-b_{2}^{\prime}\right)<0$

Therefore, the profit function is concave with respect to the retailer's selling price. 


\subsection{Numerical example}

This research used the following numerical example to illustrate the applicability of the proposed model. The values of the variables are expressed as, $P_{s}=10, A_{s}=100, P_{s}^{\prime}=$ $8, C_{s}=1.5, h_{s}=2, A_{m}=250, D_{m}=60, D_{r}=58, D_{c}^{\prime}=6, x=0.2, y=0.02, z=0.2, \alpha=20, \beta=$ $0.02, C_{m}=1, h_{m}=1, h_{m}^{\prime}=0.5, f_{c}=8, A_{r}=150, A_{m}^{\prime}=80, S_{m}=60, C_{r}=0.8, h_{r}=1, a=$ $25, b_{1}=0.45, b_{1}^{\prime}=0.3, b_{2}=0.3, b_{2}^{\prime}=0.1, S_{s}=15, S_{m}^{\prime}=40, S_{e}=100 . \quad$ This $\quad$ study also performs sensitivity analysis on variables $y, b, a$, and $b_{1}$.

\section{Results and Discussion}

The optimum results are shown in Table 1. It can be seen that the supply chain's total profit was more in the integrated approach than the leader-follower relationship method, or in other words, the supply chain performed better when its players worked in an integrated way. This table also shows that the retailer's selling price was significantly lower in the integrated approach, which is a vital aim of a supply chain. Also, the lot size of the supplier was larger in the second approach. However, the manufacturer's production rate was lower in this method.

Table 1. Optimum results of example

\begin{tabular}{crrrrrrrr}
\multicolumn{2}{l}{ Leader-follower relationship strategy } & \multicolumn{4}{c}{ Integrated approach } \\
\hline$Q$ & $p_{m}$ & $S_{r}$ & $\Pi_{\mathrm{L}}$ & $Q$ & $p_{m}$ & $S_{r}$ & $\Pi_{\mathrm{I}}$ \\
\hline 124.97 & 87.41 & 105.54 & 1271.85 & 160.05 & 64.05 & 86.27 & 1323.79
\end{tabular}

This research studied the effect of change in some parameters on the supply chain profit and the optimum decision variables depicted in Table 2 to Table 4 . The effect of changing y can be seen in Table 2. With the increase in the variable $y$, the lot size of the supplier increased. However, the total supply chain profit decreased in both approaches.

The effect of change in $\beta$ is described in Table 3 . It shows that the increase in $\beta$ value was directly proportional to the increase in $\Pi_{m}$. As the value of the learning parameter increased, the profit of the supply chain increased, which was quite practical. A change in the variable $\alpha$ yielded different scenario (Table 4), where the profit decreased sharply with the increase in this parameter. The profit of the supply chain in both approaches decreased sharply with the increase in parameter $b_{1}$ (Table 5).

Table 2. Effect of change in $y$

\begin{tabular}{|c|c|c|c|c|}
\hline \multirow[t]{2}{*}{ Changing variable $(y)$} & \multicolumn{2}{|c|}{ Leader-follower relationship } & \multicolumn{2}{|c|}{ Integrated approach } \\
\hline & $Q$ & $\Pi_{L}$ & $Q$ & $\Pi_{I}$ \\
\hline 0.01 & 123.71 & 1273.94 & 159.11 & 1324.8 \\
\hline 0.02 & 124.97 & 1271.85 & 160.05 & 1323.79 \\
\hline 0.03 & 126.26 & 1269.71 & 160.99 & 1322.77 \\
\hline 0.04 & 127.58 & 1267.54 & 161.94 & 1321.74 \\
\hline
\end{tabular}


Table 3. Effect of change in $\beta$

\begin{tabular}{lll} 
Changing variable $(\beta)$ & Leader-follower approach & Integrated approach \\
\cline { 2 - 3 } & $\Pi_{m}$ & $\Pi_{m}$ \\
& & \\
0.02 & 456.29 & 868.67 \\
0.04 & 456.62 & 869.71 \\
0.06 & 456.94 & 870.71 \\
0.08 & 457.25 & 871.68
\end{tabular}

Table 4. Effect of change in $\alpha$

\begin{tabular}{lll}
\hline Changing variable $(\alpha)$ & Leader-follower relationship $\left(\Pi_{m}\right)$ & Integrated approach $\left(\Pi_{m}\right)$ \\
\cline { 2 - 3 } & & \\
\hline 20 & 456.29 & 868.67 \\
\hline 25 & 372.96 & 669.10 \\
\hline 30 & 289.63 & 487.96 \\
\hline 35 & 206.29 & 325.29 \\
\hline
\end{tabular}

Table 5. Effect of change in $b_{1}$

\begin{tabular}{lll}
\hline Changing variable $\left(b_{1}\right)$ & Leader-follower relationship $\left(\Pi_{L}\right)$ & Integrated approach $\left(\Pi_{I}\right)$ \\
\hline 0.40 & 1514.98 & 1672.47 \\
\hline 0.45 & 1263.99 & 1323.79 \\
\hline 0.50 & 1056.44 & 1075.88 \\
\hline 0.55 & 859.45 & 890.94 \\
\hline
\end{tabular}

\section{Conclusion}

This supplier-manufacturer-retailer supply chain model includes some practical factors like inspection error, the learning effect of the employees on the production cost, and the use of dual-channel by the retailer for selling the products. Besides, the manufacturer offers a return policy to the retailer to entice them to purchase more products. The manufacturer reworks the defective products, including those returned from the retailer, and sells these directly to the customers as refurbished products at a reduced price (as these products may still fail to function, harming the brand reputation). In these scenarios, the derivation of the profit functions of all SC players and the entire SC system ensued. The Leader-follower relationship method and integrated approach were employed to solve this model.

The numerical result shows that when the supply chain players optimize their decisions together in an integrated way, the supply chain gains more profit. Also, it was possible to sell the products to the customers at a reasonable price when using the integrated approach. Therefore, this model found the beneficial impact of the learning effect on the SC profit.

Researchers can extend this model in various ways. Most importantly, researchers can extend this model by adding one or more supply chain players. Furthermore, 
researchers can also consider the customers' demand for the product to the retailer as fuzzy, stochastic, stock dependent.

\section{Data Availability}

All data generated or analyzed during this study are included in this article.

\section{Declarations}

Author contribution: This paper is research written by Sujata Saha.

Funding statement: No funding was received for this study.

Conflict of interest: The authors declare no conflict of interest.

Additional information: No additional information is available for this paper.

\section{Acknowledgment}

We thank the anonymous reviewers for their careful reading of our paper and their many insightful comments and suggestions.

\section{References}

[1] S. Saha and T. Chakrabarti, "Cost Minimization Policy for Manufacturer in a Supply Chain Management System with Two Rates of Production under Inflationary Condition," Jurnal Teknik Industri, vol. 21, no. 2, pp. 200-212, 2020. https://doi.org/10.22219/JTIUMM.Vol21.No2.200-212.

[2] M. F. Ibrahim and M. M. Putri, "Integrated Green Supply Chain Model to Reduce Carbon Emission with Permissible Delay-in-Payment Consideration," Jurnal Teknik Industri, vol. 20, no. 2, pp. 128-139, 2019. https://doi.org/10.22219/JTIUMM.Vol20.No2.128-139.

[3] D. M. Utama, H. M. Kholik, and A. F. Mulya, "Integrated Procurement-Production Inventory Model with Two-Stage Production," Jurnal Teknik Industri, vol. 21, no. 2, pp. 185-199, 2020. https://doi.org/10.22219/JTIUMM.Vol21.No2.185-199.

[4] A. K. Manna, J. K. Dey, and S. K. Mondal, "Two layers supply chain in an imperfect production inventory model with two storage facilities under reliability consideration," Journal of Industrial and Production Engineering, vol. 35, no. 2, pp. 57-73, 2018. https://doi.org/10.1080/21681015.2017.1415230.

[5] M. Rokhim, "Penentuan Key Performance Indicator Dengan Metode Balanced Scorecard," Jurnal Teknik Industri, vol. 18, no. 2, pp. 168-175, 2017. https://doi.org/10.22219/JTIUMM.Vol18.No2.168-175.

[6] S. Saha and T. Chakrabarti, "Two-echelon supply chain model for deteriorating items in an imperfect production system with advertisement and stock dependent demand under trade credit," International Journal of Supply Operations Management, vol. 5, no. 3, pp. 207-217, 2018. http://doi.org/10.22034/2018.3.5.

[7] A. Dityarini, E. Pujiyanto, and I. W. Suletra, "Multi-Objective Optimization Model of Multi-Pass Turning Operations to Minimize Energy, Carbon Emissions, and Production Costs," Jurnal Teknik Industri, vol. 21, no. 2, pp. 213-224, 2020. https://doi.org/10.22219/JTIUMM.Vol21.No2.213-224.

[8] X. Lai, Z. Chen, B. C. Giri, and C.-H. Chiu, "Two-Echelon Inventory Optimization for Imperfect Production System under Quality Competition Environment," Mathematical Problems in Engineering, vol. 2015, p. 326919, 2015. https://doi.org/10.1155/2015/326919. 
[9] B. Sarkar and I. Moon, "An EPQ model with inflation in an imperfect production system," Applied Mathematics and Computation, vol. 217, no. 13, pp. 6159-6167, 2011. https://doi.org/10.1016/j.amc.2010.12.098.

[10] O. Dey, "A fuzzy random integrated inventory model with imperfect production under optimal vendor investment," Operational Research, vol. 19, no. 1, pp. 101115, 2019. http://doi.org/10.1007/s12351-016-0286-1.

[11] P. Gautam and A. Khanna, "An imperfect production inventory model with setup cost reduction and carbon emission for an integrated supply chain," Uncertain Supply Chain Management, vol. 6, no. 3, pp. 271-286, 2018. https://doi.org/10.5267/j.uscm.2017.11.003.

[12] A. K. Manna, B. Das, J. K. Dey, and S. K. Mondal, "Two layers green supply chain imperfect production inventory model under bi-level credit period," Tékhne, vol. 15, no. 2, pp. 124-142, 2017. https://doi.org/10.1016/j.tekhne.2017.10.001.

[13] S. R. Singh and V. Gupta, "Vendor -Buyer Model with Error in Quality Inspection and Selling Price Dependent Demand Rate under the Effect of Volume Agility," ijoqm, vol. 22, pp. 357-371, 2017.

[14] W. Jauhari, R. Sulistyanto, and P. Laksono, "Coordinating a two-level supply chain with defective items, inspection errors and price-sensitive demand," Songklanakarin Journal of Science and Technology, vol. 40, 2016. https://doi.org/10.14456/sjst-psu.2018.2.

[15] S. Saha, "A Three-Echelon Dual Channel Supply Chain Model with Learning Effect Under Return Policy," Jurnal Teknik Industri, vol. 22, no. 2, pp. 450-469, 2017 2021. https://doi.org/10.1504/IJMOR.2017.087740.

[16] S. Saha and T. Chakrabarti, "A supply chain model under return policy considering refurbishment, learning effect and inspection error," Croatian Operational Research Review, vol. 11, no. 1, pp. 53-66, 20202020. https://doi.org/10.17535/crorr.2020.0005.

[17] S. Saha and T. Chakrabarti, "A Multi-Storehouse Supply Chain Considering Systems' Reliability and Free Shipping," IUST, vol. 32, no. 3, pp. 1-12, 2021. https://doi.org/10.22068/ijiepr.32.3.9.

[18] S. Pal and G. S. Mahapatra, "A manufacturing-oriented supply chain model for imperfect quality with inspection errors, stochastic demand under rework and shortages," Computers \& Industrial Engineering, vol. 106, pp. 299-314, 2017. https://doi.org/10.1016/j.cie.2017.02.003.

[19] A. K. Maity, K. Maity, S. K. Mondal, and M. Maiti, "A production-recyclinginventory model with learning effect," Optimization Engineering, vol. 10, no. 3, pp. 427-438, 2009 2009. https://doi.org/10.1007/s11081-009-9084-4.

[20] Y.-C. Tsao, T.-H. Chen, and P.-Y. Wu, "Effects of Lot-Sizing Integration and Learning Effect on Managing Imperfect Items in a Manufacturer-Retailer Chain," Journal of Applied Mathematics, vol. 2013, p. 413206, 2013. http://doi.org/10.1155/2013/413206.

[21] R. Yadav, S. Pareek, M. Mittal, I. Sangal, and M. K. Jayaswal, "Effect of Learning on Optimal Policies of Supply Chain Partners for Imperfect Quality Items: Game Theoretic Approach," in 2019 Amity International Conference on Artificial Intelligence (AICAI), 2019, pp. http://doi.org/10.1109/AICAI.2019.8701410.

[22] J. Zhou, R. Zhao, and W. Wang, "Pricing decision of a manufacturer in a dualchannel supply chain with asymmetric information," European Journal of Operational Research, vol. 278, no. 3, pp. 809-820, 2019. https://doi.org/10.1016/j.ejor.2019.05.006. 
[23] Y. Zu, L. Chen, and Y. Fan, "Research on low-carbon strategies in supply chain with environmental regulations based on differential game," Journal of Cleaner $\begin{array}{lllll}\text { Production, } & \text { vol. } & \text { 177, } & \text { pp. } & 527-546,\end{array}$ https://doi.org/10.1016/j.jclepro.2017.12.220.

[24] J. Heydari, K. Govindan, and A. Aslani, "Pricing and greening decisions in a threetier dual channel supply chain," International Journal of Production Economics, vol. 217, pp. 185-196, 2019. https://doi.org/10.1016/j.ijpe.2018.11.012.

[25] Y. Zhou and X. Ye, "Differential game model of joint emission reduction strategies and contract design in a dual-channel supply chain," Journal of Cleaner $\begin{array}{llll}\text { Production, } & \text { vol. } & \text { 190, } & \text { pp. }\end{array}$ https://doi.org/10.1016/j.jclepro.2018.04.133.

[26] M. Noori-daryan and A. A. Taleizadeh, "Optimizing pricing and ordering strategies in a three-level supply chain under return policy," Journal of Industrial Engineering International, vol. 15, no. 1, pp. 73-80, 2019. http://doi.org/10.1007/s40092-018-0262-x.

[27] R. Batarfi, M. Y. Jaber, and S. M. Aljazzar, "A profit maximization for a reverse logistics dual-channel supply chain with a return policy," Computers \& Industrial Engineering, vol. 106, pp. 58-82, 2017. https://doi.org/10.1016/j.cie.2017.01.024.

[28] I. Blanco-Montenegro, R. De Ritis, and M. Chiappini, "Imaging and modelling the subsurface structure of volcanic calderas with high-resolution aeromagnetic data at Vulcano (Aeolian Islands, Italy)," Bulletin of Volcanology, vol. 69, no. 6, pp. 643659, 2014 2007. http://doi.org/10.1007/s00170-014-5645-6.

[29] G. Li, L. Li, S. P. Sethi, and X. Guan, "Return strategy and pricing in a dualchannel supply chain," International Journal of Production Economics, vol. 215, pp. 153-164, 2019. https://doi.org/10.1016/j.ijpe.2017.06.031.

[30] B. K. Mawandiya, J. Jha, and J. J. Thakkar, "Optimal production-inventory policy for closed-loop supply chain with remanufacturing under random demand and return," Operational Research, vol. 20, no. 3, pp. 1623-1664, 20182020. http://doi.org/10.1007/s12351-018-0398-x. 